\section{AB0052 TREATMENT WITH BACTERICIDAL/PERMEABILITY- INCREASING PROTEIN REDUCES CRYSTAL-INDUCED INFLAMMATION AND COLLAGEN-INDUCED ARTHRITIS IN MICE}

\author{
A. Scanu ${ }^{1}$, R. Luisetto ${ }^{2}$, B. Raffeiner ${ }^{1}$, L. Corain ${ }^{3}$, P. Galozzi ${ }^{1}$, R. Ramonda ${ }^{1}$ \\ F. Oliviero ${ }^{1}$, L. Punzi ${ }^{1} .{ }^{1}$ Rheumatology Unit, ${ }^{2}$ Dept. of Experimental Surgery, ${ }^{3}$ Dept. \\ of Management and Engineering, University of Padova, Padova, Italy
}

Background: Bactericidal/permeability-increasing protein (BPI) is an antibacterial glycoprotein produced by polymorphonuclear cells (PMN). Although BPI has been detected in synovial fluid of patients with different type of arthritis, its effects in these diseases remain unexplored.

Objectives: To investigate the effects of $\mathrm{BPI}$ in mouse models of crystal-induced inflammation and collagen-induced arthritis (CIA).

Methods: Air pouches were raised on the backs of CD1 mice ( $n=14$ per condition). $2 \mathrm{mg}$ of calcium pyrophosphate (CPP) crystals in $1 \mathrm{ml}$ of PBS were injected into the pouch in the presence or absence of $0.1 \mathrm{mg}$ of BPI for 3 hour. Controls received $1 \mathrm{ml}$ of PBS. After the sacrifice, pouch fluids were recovered by washing with $2 \mathrm{ml}$ of PBS. Leukocyte count in lavage fluids was obtained using a hemocytometer and the PMN percentage was determined by May-Grünwald-Giemsa staining. $\mathrm{ClA}$ was induced in $\mathrm{C} 57 \mathrm{BI} / 6$ mice ( $\mathrm{n}=12$ per condition) by immunisation with collagen/complete Freund's adjuvant emulsion at days 0 and 21. Arthritis was monitored by measuring paw swelling with a calliper and scored (0-5) every 2 days. Arthritic mice (paw score $=2$ ) were intraperitoneally injected with $200 \mu \mathrm{l}$ of $\mathrm{BPI}(50 \mu \mathrm{g} / \mathrm{ml})$ or vehicle only (PBS). Treatment and arthritis evaluation were carried out twice a week for 2 month. At the experiment endpoints, mice were subjected to knee and ankle ultrasound (US) and then euthanized. Hind paws were processed for histological analysis to assess inflammation, pannus formation, cartilage and bone destruction in knee and ankle joints (score $0-5$ ). IL-1 $\beta$, IL-6, CXCL1 and TNF levels were measured by ELISA in pouch fluids and serum from collected blood.

Results: The injection of CPP crystals into the pouches induced leukocyte infiltration $\left(26.27 \pm 4.14 \times 10^{5}\right.$ cells $\left./ \mathrm{ml}\right)$ comprising $73.5 \% \pm 2.12 \%$ of PMN. IL-1 $13(80.99$ $\pm 3.65 \mathrm{pg} / \mathrm{ml}), \mathrm{lL}-6(892.90 \pm 28.14 \mathrm{pg} / \mathrm{ml}), \mathrm{CXCL} 1(762.82 \pm 50.08 \mathrm{pg} / \mathrm{ml})$ and TNF $(52.70 \pm 0.49 \mathrm{pg} / \mathrm{ml})$ were measured in lavage fluids. The co-injection of crystals and BPI inhibited leukocyte influx by $67 \%$ and PMN infiltration by $55 \%$ and, in turn, the levels of all assessed cytokines were reduced ( $46 \%$ IL- $1 \beta, 35 \%$ IL- 6 , $60 \%$ CXCL1, 64\% TNF). CIA mice reached an arthritis score of 2 after $28-33$ days and showed a progressive worsening of clinical signs that picked at day 49-56, and then improved only in BPI group. At the end of the experiment, hind paw swelling and scores were lower in BPI-mice (paw thickness $=4.76 \pm 0.33 \mathrm{~mm}$; score $=4$ \pm 0.5 ) than in controls (paw thickness $=6.39 \pm 0.95 \mathrm{~mm}$; score $=5$ ). US revealed synovial hypertrophy in all joints considered, but the presence of effusion only in knees of untreated animals. Power Doppler was positive in controls but not in BPI group. BPI decreased histological scores for pannus formation and inflammation by 3 -fold, and for cartilage and bone destruction by 2-fold as compared to PBSmice. CIA induction led to high levels of IL-1 $3(656.80 \pm 45.6 \mathrm{pg} / \mathrm{ml})$, IL-6 $(376.04$ $\pm 46.33 \mathrm{pg} / \mathrm{ml})$, CXCL1 $(834.08 \pm 68.8 \mathrm{pg} / \mathrm{ml})$ and TNF $(277.72 \pm 15.24 \mathrm{pg} / \mathrm{ml})$, which were reduced with BPI treatment by $66 \%, 46 \%, 47 \%$ and $93 \%$, respectively.

Conclusions: This study shows inhibitory effects of BPI on crystal-induced inflammation and $\mathrm{ClA}$, suggesting a therapeutic potential of this protein for arthritis by down-regulating inflammatory process.

Disclosure of Interest: None declared

DOI: 10.1136/annrheumdis-2018-eular.2674

\section{AB0053 A BIOASSAY TO MEASURE TGFB ACTIVITY REVEALS DECREASED TGFB ACTIVITY IN SSC SERUM}

A. Van Caam ${ }^{1}$, E. Vitters ${ }^{1}$, F. van den Hoogen ${ }^{2}$, M. Vonk ${ }^{2}$, P. van der Kraan ${ }^{1}$. ${ }^{1}$ Experimental Rheumatology, ${ }^{2}$ Rheumatology, RADBOUDUMC, Nijmegen, Netherlands

Background: Systemic sclerosis (SSc) is a severe disease characterised by auto-immunity, vasculopathy and excessive fibrosis of connective tissues. The pathophysiology of SSc is still poorly understood, but its symptoms imply a role for dysregulated transforming growth factor $\beta$ (TGF $\beta$ ) signalling; e.g. this cytokine is known to regulate vascular and connective tissue biology. TGF $\beta$ circulates in blood in an inactive form bound to latency associated peptide and latent TGF $\beta$ binding proteins. This latent TGF $\beta$ first has to be activated before it can become bioactive. With the use of a bioassay, TGF $\beta$ 's bioactivity can be measured in a complex mixture like serum, unlike with an ELISA which cannot take cellular activation processes into account.

Objectives: To determine the bioactivity of TGF $\beta$ in SSc serum compared to that of healthy control serum

Methods: Serum was collected of $10 \mathrm{SSc}$ patients and 10 age and sex matched healthy controls. Primary human fibroblasts of 3 donors were transduced with $\mathrm{CAGA}_{12}$-luc which produces luciferase in response to TGF $\beta /$ Smad3 or BRE-luc which produces luciferase in response to BMP/Smad1/5. These cells were treated with $10 \%$ serum for 16 hour and luciferase activity was measured. To activate all TGF $\beta$, sera were treated with $4 \mathrm{M} \mathrm{HCl}$ for 1 hour at $\mathrm{RT}$, after which $\mathrm{pH}$ was normalised with $4 \mathrm{M} \mathrm{NaOH}$. Controls were treated with $\mathrm{HCl}$ and $\mathrm{NaOH}$ simultaneously. To verify that TGF $\beta$ signalling was measured in this reporter assay, sera were treated with anti-TGF $\beta 1 / 2 / 3$ for 1 hour at $\mathrm{RT}$ before use.

Results: Control sera significantly induced reporter activity by 4.5 -fold. However, SSc sera only induced a 2.5 -fold increase in luciferase activity, indicating significantly lower bioactivity of TGF $\beta(p<0.0001)$. This difference was not due to a difference in total TGF $\beta$ levels; after activation of all TGF $\beta$ both HC and SSc sera induced a similar 6 -fold increase in signal strength. These data show that in $\mathrm{HC}$ sera approximately $75 \%$ of all TGF $\beta$ is bioactive compared to only $42 \%$ in SSc. Addition of anti-TGF $\beta 1 / 2 / 3$ inhibited all CAGA A $_{12}$-luc reporter activity $(p<0.0001)$ of both $\mathrm{HC}$ and SSc serum, and of both acidified and not acidified sera $(p<0.0001)$ showing that our bioassay is indeed TGF $\beta$-dependent. To investigate if reduced bioactivity is a more general phenomenon we measured BMP activity. BMP proteins are structurally closely related to TGF $\beta$ and also circulate in inactive form. Both $\mathrm{HC}$ and SSc sera induced a similar 8-fold increase in BRE-luc activity, and this activity was increased to a 16 -fold induction after acidification for both groups. BMPs in SSc sera are thus not less bioactive. This illustrates the uniqueness of our observation on TGF $\beta$ bioactivity.

Conclusions: TGF $\beta$ in SSc serum is less bioactive than in control serum whereas BMPs are not less bioactive.

Disclosure of Interest: None declared

DOI: 10.1136/annrheumdis-2018-eular.6346

\section{AB0054 PDE4 INHIBITOR ATTENUATION OF IL-23 SECRETION FROM MONONUCLEAR CELLS}

C. Bridgewood, R. Cuthbert, M. Wittmann, D. McGonagle. Leeds Institute of Rheumatic and Musculoskeletal Medicine, University of Leeds, Leeds, UK

Background: IL-23 is a cytokine heavily implicated in the immunopathology of both psoriasis and psoriatic arthritis. Emerging evidence suggest IL-36 $\lambda$, a novel inflammatory cytokine which has been heavily implicated in psoriatic immunopathology, is able to stimulate the release of IL-23. ${ }^{1-3}$ PDE4 inhibitors, which elevate cyclic AMP (cAMP) are known to exert anti-inflammatory effects by regulating transcription factors such as NF- $\mathrm{BB}$. The PDE4 inhibitor, Apremilast has proved successful in treating both psoriasis and psoriatic arthritis with patients showing a decrease in inflammatory cytokine levels, including IL-23. ${ }^{4}$ However, the ability and mechanism of PDE4 inhibitors to lower IL-23 secretion from immune cells induced by disease relevant stimuli is presently unknown. Additionally, any potential relationship between IL-36 $\lambda$ driven inflammation and potential PDE4 inhibition is yet to be determined.

Methods: Blood mononuclear cells from healthy patients, $(n=5)$ were pretreated with either the PDE4 inhibitor Rolipram or other compounds known to elevate cAMP levels, such as histamine and 8-bromo-cAMP. Cells were subsequently treated with either bacterial or fungal toll like receptor adjuvants (LPS and Mannan) or the novel psoriatic cytokine IL-36 $\lambda$. IL-23 was subsequently measured in culture supernatants by ELISA and by intracellular IL23p19 flow cytometry.

Results: LPS, Mannan and IL-36 $\lambda$ all induced IL-23 secretion which could be attenuated in a dose dependent manner by the PDE4 inhibitor, Rolipram. Other compounds also known to increase cAMP levels, histamine and 8-bromo-cAMP similarly were able to reduce IL-23 secretion from all stimuli.

Conclusions: This data suggests a direct link between PDE4 inhibition and reduced IL-23 secretion in circulating immune cells. Additionally, it provides insight into of how IL36/IL-23/IL-17 driven inflammation may be reduced by PDE4 inhibitors in psoriasis and psoriatic arthritis.

\section{REFERENCES:}

[1] Gabay C, Towne JE. Regulation and function of interleukin-36 cytokines in homeostasis and pathological conditions. J Leukoc Biol 2015;97(4):645652.

[2] Chi $\mathrm{HH}$, et al. IL-36 Signaling Facilitates Activation of the NLRP3 Inflammasome and IL-23/IL-17 Axis in Renal Inflammation and Fibrosis. J Am Soc Nephrol 2017;28(7):2022-2037.

[3] Bridgewood C, et al. IL-36 $\gamma$ is a strong inducer of IL-23 production and angiogenesis in psoriasis. Frontiers in Immunology 2018;9:200.

[4] Keating GM. Apremilast: A Review in Psoriasis and Psoriatic Arthritis. Drugs 2017;77(4):459-472.

Disclosure of Interest: None declared

DOI: 10.1136/annrheumdis-2018-eular.7287 